Bangladesh Journal of Neuroscience 2015; Vol. 31 (2): 70-75

\title{
Efficacy of low-dose Topiramate in Migraine Prophylaxis
}

\author{
MUHAMMAD ABDUL MOMEN KHAN ${ }^{1}$, MOHAMMAD BAHADUR ALI MIAH ${ }^{2}$, MD.SHAHIDULLAH ${ }^{2}$, \\ MD. RAFIQUL ISLAM ${ }^{3}$, SUBASH KANTI DAY ${ }^{2}$, JANNATUL FERDOUS ${ }^{4}$, MD. AMIR HOSSAIN ${ }^{5}$
}

\begin{abstract}
:
Background: Anticonvulsants are now commonly used for migraine prophylaxis, among them topiramate, one of the newer anticonvulsants, recently has been demonstrated to be effective as mono-therapy for migraine prophylaxis. Objectives: To observe the efficacy and safety of low dose topiramate in migraine prophylaxis. Methods: This prospective trial was carried out in the Out Patient Department (OPD) \& Headache Clinic, Department of Neurology, Bangabandhu Sheikh Mujib Medical University, Dhaka. Total 60 patients around the age range of 18 to 50 years diagnosed as migraine (with aura or without aura) according to ICHD-3 criteria, were recruited as the study population. Total 60 patients were administered by Tab. Topiramate $50 \mathrm{mg} /$ day. Out of them, total 47 patients had completed the study due to drop out of 13 patients. During trial, three follow up visits were taken, $1^{\text {st }}$ follow up after 4 weeks of baseline information (Before starting prophylactic medication), $2^{\text {nd }}$ follow up after 4 weeks of treatment, $3^{\text {rd }}$ follow up after 8 weeks of treatment. Efficacy of treatment was measured by headache frequency, duration and severity as measured by the VAS. Effectiveness was assessed by comparing baseline \& on-treatment migraine status. Results: The mean (SD) age of patients were found 29.72 (9.58) years. Female sex was predominant. The mean (SD) value of frequency of migraine at baseline level with $1^{\text {st }}$ and $2^{\text {nd }}$ follow up were statistically significant [Baseline $9.28(2.39)$ vs. $1^{\text {st }} \mathrm{FU} 7.55$ (3.07), $p=0.001$; Baseline 9.28 (2.39) vs. $2^{\text {nd }} F U 4.72$ (2.80), $p<0.001$ ]. Duration of each episode of migraine, comparing the mean $(S D)$ value of duration of migraine of baseline level with $1^{\text {st }}$ and $2^{\text {nd }}$ follow up were statistically significant [Baseline $10.85(5.26) \mathrm{vs}$. $1^{\text {st }}$ FU 8.06 (4.11) hr, p<0.001; Baseline 10.85 (5.26) vs. $2^{\text {nd }} F U 5.53$ (2.98) hr, $\left.p<0.001\right]$. According to severity of migraine based on VAS in base line period all patients had experienced moderate \& severe headache but in $1^{\text {st }}$ follow up, few patients had experienced mild headache from moderate headache, few patients had experienced moderate headache from severe headache \& in $2^{\text {nd }}$ follow up, patients had better condition and had experienced mild and moderate headache, no patient had experienced severe headache. In this study, $23.4 \%$ patients developed adverse effects. Among the adverse effects, $8.5 \%$ develop dizziness, $6.3 \%$ drowsiness, $4.2 \%$ anorexia \& blurring of vision. Conclusion: The present study suggest that low dose topiramate are effective for migraine prophylaxis in reduction of frequency, severity and duration of migraine headache .
\end{abstract}

Key words: Efficacy, low-dose Topiramate, Migraine

Abbreviations: VAS- Visual Analogue Scale, ICHD- International Classification of Headache Disorder, SD- Standard Deviation

Introduction:

Migraine is an episodic central nervous system disorder characterized by vascular headache associated with vasodilatation of extra-cranial vessels but may be due to disturbed neuronal activity in the hypothalamus ${ }^{1}$. Migraine headache ranges from moderate to very severe in intensity and lasts from 4 to 72 hours ${ }^{2}$, often accompanied by photophobia, phonophobia and vomiting ${ }^{3}$.

According to World Health Organization (WHO) migraine is the global burden of health related issue. That study was conducted in 2000 and was reported

1. Assistant Professor, Department of Neurology,Manikgonj Medical college

2. Associate Professor, Department of Neurology, BSMMU

3. Professor, Department of Neurology, BSMMU

4. Resident, Department of Paediatrics, SSMC \& Mitford Hospital

5. Assistant Professor, Department of Neurology,SBMC,Barisal 
in the World Health Report 2001. Migraine included for the first time in years lived with disability (YLD) \& contributing $1.4 \%$ of YLD, is the $19^{\text {th }}$ cause of disability in both sexes of all ages $\& 12^{\text {th }}$ in case of women, accounting for $2.0 \%$ of YLD, in case of women ${ }^{4}$. Successful management of migraine requires intensive patient's educations and through physician knowledge about available treatment options and strategies. Use of a prophylactic medication reduces headache duration, frequency, severity and risk for rebound headache ${ }^{5}$.

Migraine is a common condition, annually affecting $12 \%$ of the United States population, including $18 \%$ of women, $6 \%$ of men and $4 \%$ of children. Migraine is generally more common in people who are in lower socioeconomic groups ${ }^{6}$.

In Bangladesh there is no data regarding the prevalence of migraine. In a study conducted in BSMMU headache clinic total 3440 of headache patients were studied and $16.05 \%$ of them had a diagnosis of migraine ${ }^{7}$.

Different elements need to be considered in migraine management. They include: avoidance of triggering factors, lifestyle modifications, non-pharmacological therapies and lastly medications. Pharmacological treatment is traditionally divided into acute treatment, and preventive treatment. Many migraine patients can be treated using only acute treatment that are used only during headache attacks to abort an ongoing attack or to stop its progression to severe pain and associated symptoms. Patients with severe and/or frequent migraine require longterm preventive therapy ${ }^{8}$.

Prophylaxis is recommended to reduce the frequency and/or intensity of migraine headaches when patients experience more than three to five attacks per month. A variety of drugs from diverse pharmacological classes are in use for migraine prevention. Adrenergic receptor blockers (e.g. propranolol), tricyclic antidepressants (e.g. amitriptyline), anticonvulsants (e.g. topiramate and valproate), and serotonergic drugs (e.g. methysergide) are most commonly administered for this purpose, as summarized in US Headache Consortium Guidelines .More recently, topiramate was tested prospectively. Topiramate showed statistically significant efficacy in migraine prevention .Topiramate appeared to be safe and had an acceptable safety profile. Among several treatment-emergent adverse events dose dependent weight loss is common. For these reason, slow titration of target dose of topiramate is advisable ${ }^{9}$.

The impact of migraine on the sufferer and his or her productivity in national level is innumerable. For the last decade, anticonvulsants are in use as prophylactic medication for migraine, among which sodium divalproex \& sodium valproate are the most studied. For the last few years, high dose (100- 200 $\mathrm{mg} /$ day) of topiramate was used in migraine prophylaxis, but with such high doses, usually significant side effect could have occurred.

In this context, the present study was designed to observe the effect of low dose topiramate $(50 \mathrm{mg} /$ day) in migraine prophylaxis

\section{Materials and Methods:}

A clinical trial was conducted in Out Patient Department (OPD) \& Headache Clinic, Department of Neurology, BSMMU, Dhaka. Informed written consent was taken from all patients. Migraine was diagnosed according to the criteria of the Headache Classification Committee of the International Headache Society, 2013(ICHD-3). Considering 10\% drop out in every follow up, sample size was 60 . A total 60 patients were selected according to selection criteria.

\section{Inclusion criteria}

1. Patient of migraine (with typical aura or without aura) according to ICHD-3 criteria.

2. Age at entry: 18-50 years.

3. Patients not on any prophylactic medication.

4. Patients willing to take part in the study.

5. Patient being able to fill a headache diary successfully \& reliably.

\section{Exclusion criteria}

1. Age $<18$ years or $>50$ years.

2. Patients having headache other than migraine.

3. Patients on prophylactic medication.

4. Any co-morbidity such as hepatic or renal impairment, malignancy, intracranial vascular aneurysm, pregnancy \& breastfeeding etc. 
5. Patients not willing to take part in the study.

6. Patient having known hypersensitivity to topiramate

Detailed history, general examination, neurological examination, routine laboratory investigations and other relevant investigations were carried out accordingly. They were taught to maintain their headache character on a headache diary supplied to them \& advised them to report at the headache clinic after 4 weeks. Intensity of headache was measured by Visual Analogue Scale (VAS). VAS is graded as mild, moderate and severe in intensity.

The analysis was done by comparing the number of days (duration) with headache, frequency and intensity of headache according to visual analogue pain scale before starting of prophylaxis and that of 4 weeks and 8 weeks after treatment. Outcome measured were reduction of visual analogue pain scale score, duration and frequency of acute attacks of headache compared to the baseline with subsequent follow up, adverse effects were individually registered. The trial evolved into 2 stages:

Stage-1(4 weeks): The base line period or medication( Topiramate) free period. During this period the subjects were taught to fill their headache diary to record the baseline headache characters, they act as control group in this study. Those who filled the headache diary reliably entered into the stage-2. Stage- 2(8 weeks): Tab.Topiramate was given \& headache character was recorded by the patients themselves on headache diary. Patient was treated by Tab Topiramate $25 \mathrm{mg}$ at night for 1 week, followed by $25 \mathrm{mg}$ twice daily for another 7 weeks. Continuous data were expressed as mean and standard deviation and qualitative data were expressed as frequency distribution and percentage. Statistical analysis was performed by using SPSS-21. Data were analyzed by Wilcoxon signed ranks test as data shows asymmetric distribution. For all statistical tests, we considered $p$ value $<0.05$ as statistically significant. Approval from the IRB of BSMMU was obtained prior to the commencement of this study.

\section{Results:}

Total 60 patients in the age range of 18 to 50 years diagnosed as migraine (with aura or without aura) according to ICHD-3 criteria, were enrolled as study population. Of them total 47 patients completed the study due to drop out of 13 patients in different steps of follow up. Table-I showed that there were $72.3 \%$ female \& $27.7 \%$ male. A total $20(42.3 \%)$ patients were in age group of 28-25 years and 12 $(25 \%)$ were in the age group of $26-35$ years(TableII).Table-III showed that there were $14.9 \%$ patients experienced aura \& $85.1 \%$ patients were free from aura.

Table-I

Study population by gender

\begin{tabular}{lcc}
\hline Gender & Number of patients & Percentage \\
\hline Female & 34 & 72.3 \\
Male & 13 & 27.7 \\
\hline Total & 47 & 100 \\
\hline
\end{tabular}

Table-II

Study population by age

\begin{tabular}{lcc}
\hline Age (year) & Number of Patients & Percentage \\
\hline $18-25$ & 20 & 42.6 \\
$26-35$ & 12 & 25.5 \\
$36-45$ & 8 & 17.00 \\
$46-50$ & 7 & 14.9 \\
\hline Total & 47 & 100 \\
\hline
\end{tabular}

Mean (SD) [yrs] 29.72 (9.58)

Range (min-max) [yrs] (18-48)

Table-III

Aura of migraine among study population

\begin{tabular}{lcc}
\hline Type of Migraine & $\begin{array}{c}\text { Number of } \\
\text { Patients }\end{array}$ & Percentage \\
\hline With Aura & 7 & 14.9 \\
Without Aura & 40 & 85.1 \\
\hline Total & 47 & 100 \\
\hline
\end{tabular}

Table-IV showed distribution of the patients according to baseline, $1^{\text {st }} \& 2^{\text {nd }}$ follow up in frequency of migraine attack , comparing the mean (SD) value of frequency of migraine attack at baseline level with $1^{\text {st }}$ and $2^{\text {nd }}$ follow up were statistically significant [Baseline 9.28 (2.39) vs. $1^{\text {st }} \mathrm{FU} 7.55$ (3.07), $p=0.001$; 
Baseline 9.28 (2.39) vs. $2^{\text {nd }} F U 4.72(2.80), p<0.001$ ] Table- $V$ shows distribution of the patients according to duration of each episode of migraine (hours) ,comparing the mean (SD) value of duration of migraine of baseline level with $1^{\text {st }}$ and $2^{\text {nd }}$ follow up were statistically significant [Baseline 10.85 (5.26) vs. $1^{\text {st }} \mathrm{FU} 8.06$ (4.11) hr, $\mathrm{p}=<0.001$; Baseline 10.85 (5.26) vs. $2^{\text {nd }} \mathrm{FU} 5.53(2.98) \mathrm{hr}, \mathrm{p}<0.001$ ]. Table-VI shows distribution of the patients according to severity of migraine based on categories of Visual Analogue Scale (VAS). During clinical trial of $1^{\text {st }}$ follow up, patients were distributed in all mild, moderate and severe groups. In $2^{\text {nd }}$ follow up, patients had better condition and distributed in mild and moderate groups. Table-VII shows distribution of patients according to adverse effects. In this study, $23.4 \%$ patients developed adverse effects. Among the adverse effects, $8.5 \%$ develop dizziness that was followed by $6.3 \%$ drowsiness.

\section{Table-IV}

Frequency of migraine attacks

\begin{tabular}{llc}
\hline Type of patients & $\begin{array}{c}\text { Frequency of } \\
\text { migraine attack } \\
\text { Mean (SD) }\end{array}$ & p-value* \\
\hline $\begin{array}{l}\text { Baseline level } \\
1^{\text {st }} \text { Follow up } \\
\text { (after 4weeks) }\end{array}$ & $\begin{array}{l}9.28(2.39) \\
\text { 2.55(3.07) }\end{array}$ & $0.001^{\text {s }}$ \\
$\begin{array}{l}2^{\text {nd }} \text { Follow up } \\
\text { (after 8weeks) }\end{array}$ & $4.72(2.80)$ & $<0.001^{\text {s }}$ \\
\hline $\begin{array}{l}\text { s=significant } \\
\text { *Wilcoxon signed ranks test was done to measure the level } \\
\text { of significance. }\end{array}$
\end{tabular}

Table-V

Duration of each episode of migraine (hours)

\begin{tabular}{lcc}
\hline Type of patients & $\begin{array}{c}\text { Duration of } \\
\text { each episode } \\
\text { of migraine (hour) } \\
\text { Mean (SD) }\end{array}$ & p-value* \\
\hline Baseline level & $10.85(5.26)$ & \\
$\begin{array}{l}1^{\text {st }} \text { Follow up } \\
\text { (after 4 weeks) }\end{array}$ & $8.06(4.11)$ & $<0.001^{\text {s }}$ \\
$\begin{array}{l}2^{\text {nd }} \text { Follow up } \\
\text { (after } 8 \text { weeks) }\end{array}$ & $5.53(2.98)$ & $<0.001^{\text {s }}$ \\
$\begin{array}{l}\text { s=significant } \\
\text { *Wilcoxon signed ranks test was done to measure the level } \\
\text { of significance. }\end{array}$
\end{tabular}

Table-VI

Severity of migraine based on Visual Analogue Scale (VAS)

\begin{tabular}{|c|c|c|}
\hline Severity of migraine & $\begin{array}{c}\text { Number of } \\
\text { patients }\end{array}$ & Percentage \\
\hline \multicolumn{3}{|l|}{ Baseline level } \\
\hline Moderate & 25 & 53.2 \\
\hline Severe & 22 & 46.8 \\
\hline \multicolumn{3}{|l|}{$1^{\text {st }}$ followup } \\
\hline Mild & 24 & 51.1 \\
\hline Moderate & 15 & 31.9 \\
\hline Severe & 8 & 17.00 \\
\hline \multicolumn{3}{|l|}{$2^{\text {nd }}$ followup } \\
\hline Mild & 29 & 61.7 \\
\hline Moderate & 18 & 38.3 \\
\hline Total & 47 & 100 \\
\hline \multicolumn{3}{|c|}{$\begin{array}{c}\text { Table-VII } \\
\text { Adverse effects among study population }\end{array}$} \\
\hline Adverse effects & $\begin{array}{l}\text { Number of } \\
\text { Patients }\end{array}$ & Percentage \\
\hline Yes & 11 & 23.4 \\
\hline Dizziness & 4 & 8.5 \\
\hline Drowsiness & 3 & 6.3 \\
\hline Blurring of vision & 2 & 4.2 \\
\hline Anorexia & 2 & 4.2 \\
\hline No & 36 & 76.6 \\
\hline Total & 47 & 100 \\
\hline
\end{tabular}

\section{Discussion:}

Various drugs have been used for migraine prophylaxis. Recently, antiepileptic drugs including topiramate (TPM) are more commonly used in adults and adolescents for migraine prophylaxis. In several randomized, double-blind, placebo-controlled, doseranging trials involving adult patients with episodic migraine, topiramate treatment resulted in significant benefit compared with placebo, with efficacy observed within the first month of treatment ${ }^{8}$.

Analysis of age distribution showed that, the mean age was found 29.72 (9.58) years and range were (18-48). A good number of the study patients were 18- 25 years age group. A study done by Dahlöf et 
al. $(2007)^{10}$ found mean (SD) age, 39.8 years who studied on topiramate placebo-controlled clinical trials. Silberstein et al. (2012) ${ }^{8}$ and Brandes et al. $(2004)^{9}$ also obtained mean age $40.4 \pm 11.5$ and $38.3 \pm 12.0$ years respectively. In this study, patients were younger than the patients of above mentioned studies.

Out of all patients, $72.3 \%$ was female and $27.7 \%$ male. Dahlöf et al $(2007)^{10}$ also found as female groups more prone to develop migraine. Diener et al. $(2004)^{11}$ and Brandes et al. $(2004)^{9}$ also found more female patients of migraine $76 \%$ and $82 \%$, respectively. These results are similar to this study.

Out of all patients, 7 (14.9\%) patients had migraine with aura \& $40(85.1 \%)$ were free from aura. Among them major portion of patients had visual aura $(12.76 \%)$, followed by sensory aura $(2.14 \%)$.

The efficacy of topiramate, based on frequency of migraine attack was observed where mean (SD) value of frequency of migraine attack of baseline level with $1^{\text {st }}$ and $2^{\text {nd }}$ follow up were statistically significant [Baseline $9.28(2.39)$ vs. $1^{\text {st }} \mathrm{FU} 7.55$ (3.07), $p=0.001$; Baseline 9.28 (2.39) vs. $2^{\text {nd }} \mathrm{FU}$ $4.72(2.80), p<0.001$ ]. Ashtari et al. $(2008)^{12}$ found that the topiramate group showed more reduction in migraine frequency, so present study results is similar with that study.

The efficacy of topiramate based on duration of each episode of migraine (hour) was observed, where mean (SD) value of duration of migraine of baseline level with $1^{\text {st }}$ and $2^{\text {nd }}$ follow up were statistically significant [Baseline 10.85 (5.26) vs. $1^{\text {st }} \mathrm{FU} 8.06$ (4.11) hr, $p<0.001$; Baseline 10.85 (5.26) vs. $2^{\text {nd }} F U$ 5.53 (2.98) hr, p<0.001]. Ashtari et al. $(2008)^{12}$ found, headache duration decreased more in topiramate group, so present study results is similar with that study .

At baseline level, patients were distributed into moderate and severe groups. During clinical trial of $1^{\text {st }}$ follow up, patients was distributed in all mild, moderate and severe groups. At the end of the trial $2^{\text {nd }}$ follow up, patients had better condition and distributed in mild and moderate group. Ashtari et al. $(2008)^{12}$ measured headache intensity, lessened more in topiramate group.
Regarding adverse effects, $23.4 \%$ patients developed adverse effects. Among the adverse effects $8.5 \%$ develop dizziness that was followed by drowsiness $6.3 \%$. Adverse effects of topiramate are $16 \%$ in the study of Silberstein et al. $(2012)^{8}$ which was relatively similar with the present study.

In present study, efficacy and adverse effect of topiramate were observed and results showed that topiramate was effective in recducing frequency and severity of headache.

\section{Conclusion:}

Considering statistical analyses, a conclusion can be made that low dose topiramate are safe and effective for migraine prophylaxis in reducing of frequency, severity and duration of migraine headache.

\section{References:}

1. Goadsby PJ, Raskin NH. Headache. In: Fauci AS, Braunwald E, Kasper DL, Hauser SL, Longo DL., Jameson JL. Harrison's Principles of Internal Medicine. $18^{\text {th }}$ ed. New York: McGraw-Hill; 2012. p.112-128

2. Silberstein SD. 'Preventive migraine treatment'. Neurol Clin 2009; 27(2): 429-43.

3. Olesen, J. 'The international classification of headache disorders. $3^{\text {rd }}$ edition (ICHD-3)'. Cephalalgia 2013; 36(1): 1-16

4. World Health Organization (WHO) (2001) The World Health Report 2001: Mental health, new understanding new hope. World Health Organization, Geneva, Switzerland. (www.who.int/whr/2001/main/en/overview/ outline.htm) (accessed on October 30, 2015)

5. Leonardi M, Steiner TJ, Scher AT, Lipton RB. 'The global burden of migraine: measuring disability in headache disorders with WHO's Classification of Functioning, Disability and Health (ICF)'. Journal of Headache Pain 2005; 6(6): 429-40.

6. Lipton RB, Stewart WF, Diamond S, Diamond $M L$, Reed M. 'Prevalence and burden of migraine in the United States: data from the American Migraine Study II'. Headache 2001; 41(7): 646-57. 
7. Hannan MA, Hasan MK, Begum A, Haque A, Anwarullah AKM, Khan MRK, Islam MR, Rahman HZ, Bhuiyan MM, Rizvi AN, Sarker DK. 'Study of epidemiological features of primary headache patients in a tertiary centre in Bangladesh'. Bangladesh Journal of Neuroscience 2007; 23(1): 11-22.

8. Silberstein SD, Dodick DW, Lindblad AS, Holoroyd K, Harrington $M$. 'Randomized, placebo-controlled trail of propranolol added to topiramate in chronic migraine'. Neurology 2012; 78:976-84.

9. Brandes JL, Saper JR, Diamond M. 'Topiramate for migraine prevention: a randomized controlled trial'. JAMA 2004; 291:965-73.
10. Dahlöf C, Elizabeth L, Merle D, Marcia R, George P. 'The impact of migraine prevention on daily activities: a longitudinal and responder analysis from three topiramate placebocontrolled clinical trials' Health and Quality of Life Outcomes 2007;5:56. Available at:www.hqlo.com/content/5/1/56 (accessed on October 30, 2015)

11. Diener HC, Tfelt-Hansen $P$, Dahlof $C$, Lainez MJ, Sandrini G. 'Topiramate in migraine prophylaxis - results from a placebo- controlled trial with propranolol as an active control'. J Neurol 2004 ; 251: 943-5.

12. Ashtari F, Shaygannejad V, Akbari M. 'Adoubleblind, randomized trial of low-dose topiramate vs propranolol in migraine prophylaxis' Acta Neurol Scand 2008;118:301-5. 